\title{
The yeast H PR 1 gene has a functional role in transcriptional elongation that uncovers a novel source of genome instability
}

\author{
Sebastián Chávez and Andrés Aguilera ${ }^{1}$ \\ Departamento de Genética, Facultad de Biología, Universidad de Sevilla, 41012 Sevilla, Spain
}

The yeast HPR 1 gene plays an important role in genome stability, as indicated by the observation that hpr 1 mutants have high frequencies of DNA repeat recombination and chromosome loss. Here we report that H PR 1 is required for transcriptional elongation. Transcription driven from constitutive and regulated yeast promoters cannot elongate through the bacterial lacZ coding region in hprls cells, but progresses efficiently through other sequences such as yeast PH 0 5. We show that H PR 1 is not required for transcription activation and that the previously reported effects of hprl $1 \Delta$ on the activation of different promoters is a consequence of the incapacity of $h p r 1 \Delta$ cells to elongate transcription through lac $Z$, used as reporter. Transcriptional defects are also observed in yeast DNA sequences of $h p r 1 \Delta$ cells in the presence of the transcription elongation inhibitor 6-azauracil. In all cases, the blockage of transcription elongetion in hprl $\Delta$ is associated with both the high frequency of deletions and the increase in plasmid instability that we report here Therefore, in addition to the identification of a new element involved in transcriptional elongation, our work provides evidence for a new source of genomic instability.

[Key Words: HPR1; transcription el ongation; transcription-induced recombination; genomic instability; DN A repeats; lacZ reporter]

Received May 21, 1997; revised version accepted October 10, 1997.

Genetic recombination is required for DN A repair in mitosis, for the generation of genetic diversity and for proper reductional division in meiosis. In addition, it is responsible for chromosomal aberrations associated with some types of cancer and hereditary diseases, many of which occur by recombination between DNA repeats. The identification of the genes and functions that control initiation of recombination between repeats is therefore essential to understand the origin of chromosome aberrations and genome instability.

One important factor affecting the frequency of initiation of recombination is transcriptional activity. Recombination is stimulated by transcription as first shown by the identification of HOT1, a sequence from the rDN A region of Saccharomyces cerevisiae required for RNA polymerase I (Pol I)-dependent transcription (Keil and Roeder 1984; Voelkel-Meiman et al. 1987). Deletions between direct repeats have also been shown to be stimulated by RNA Pol II-mediated transcription in yeast (Thomas and Rothstein 1989). The relevance of transcription in homologous recombination has also been reported in mammalian cells (N ickol off 1992; Thy-

${ }^{1}$ Corresponding author.

E-MAIL aguilo@cica.es; FAX (34) 5-4557104. agarajam et al. 1995). Probably the most significant connection between transcription and recombination is the one observed in immunoglobulin gene rearrangements (Blackwell et al. 1986; Lauster et al. 1993). Other examples of transcription-stimulated recombination have been provided in S. cerevisiae (Klar et al. 1981; NevoCaspi and Kupiec 1994), Schizosaccharomyces pombe (Grimm et al. 1991) and phages and bacteria (Dul and Drexler 1988; Vilette et al. 1992).

Transcriptional activity may induce recombination because unwinding of the DNA duplex, changes in the local supercoiling or disruption of chromatin structure associated with transcription could provide a better accessibility of recombination proteins to the transcribed DN A, could lead to DN A structures susceptible to DN A breaks, whether or not mediated by nucleases, or could facilitate the pairing reaction ( $\mathrm{M}$ cCormack and Thompson 1990; Dröge 1993; Kotani and Kmiec 1994). Other explanations cannot be excluded, however, such as a role of the transcription machinery in recruiting recombination proteins to transcribed genes that could be responsible for an increase in recombination, as is the case of transcription-coupled nucleotide excision repair (for review, see Basthia et al. 1996; Hoeijmakers et al. 1996). In this sense, the recent identification of the Rad51p re- 
combinational repair protein in the human RNA Pol II holoenzyme is noteworthy (Maldonado et al. 1996). Despite our poor understanding of the molecular basis of transcription-induced recombination, it seems cl ear that transcription is an important potential source of spontaneous recombination between repeats leading to genomic instability and needs to be investigated.

One gene particularly relevant for the understanding of the putative connection between transcription and recombination as well as for the control of direct repeat recombination in yeast is HPR1. The importance of $\mathrm{Hprlp}$ in genome stability is supported by the high frequencies of recombination and chromosome loss observed in null hpr1s mutants (Aguilera and Klein 1990; Santos-Rosa and Aguilera 1994). Hprlp has been suggested to be required for transcription activation of regulated promoters (Fan and Klein 1994; Zhu et al. 1995). Theidentification of mutations in different transcription factors as suppressors of either the thermosensitivity (Fan et al. 1996; U emura et al. 1996) or the hyper-recombination phenotype of hprl $\Delta$ (Piruat and A guilera 1996; Santos-Rosa et al. 1996) is consistent with a functional role of $\mathrm{Hprlp}$ in transcription. Our recent observations that high rates of del etions in hprls cells only occurred between direct repeats in which defined regions of the intervening sequence were transcribed (Prado et al. 1997), suggest that H prlp might have a functional rol e in transcriptional elongation. To elucidate the function of $\mathrm{H}$ prlp on transcription, whether at the initiation or the elongation stage, and to understand the causes of induction of genomic instability by $\mathrm{hpr} 1 \Delta$, we undertook an in vivo molecular analysis that has allowed us to show that: (1) Hprlp functions in transcriptional elongation, (2) previous results suggesting that $\mathrm{Hprlp}$ is a general transcriptional activator (Fan and Klein 1994; Zhu et al.
1995) are explained by the incapacity of hprl $\Delta$ cells to elongate transcription through the lac $Z$ sequence used as reporter of gene expression and not by an incapacity of hpr $1 \Delta$ cells to activate transcription at the initiation stage, and (3) the increased level s of direct repeat recombination and chromosome loss observed in hprl $\Delta$ cells is a direct consequence of the blockage of transcription elongation. Our work not only shows a functional role for H prlp in transcriptional el ongation, but al so suggests a new model for the initiation of genomic instability.

\section{Results}

HPR 1 is required for lacZ transcription

Expression of lacZ under the control of the GAL1 promoter strongly depends on HPR 1 (Fan and Klein 1994; Zhu et al. 1995) (Fig. 1B). To assess whether or not lacZ could be expressed in hprl $\Delta$ cells, the lac $Z$ coding region was placed under the control of two different constitutive promoters, TEF 2 and ADH 1 , the latter of which had been shown to promote transcription in the absence of Hprlp (Zhu et al. 1995). In contrast to the expected result, lac $Z$ was not expressed from either of the two promoters (Fig. 1C,D). The lack of $\beta$-galactosidase expression driven from the GAL1 promoter in $\operatorname{hprl} 1 \Delta$, therefore, may not be caused by a defect in transcriptional activation at the promoter. One possibility is that the lack of $\beta$-gal expression was caused by a defect in elongation through lacZ. To evaluate such a possibility, the yeast PHO5 gene was placed under the control of the GAL1 promoter. In this case, acid phosphatase was activated to wild-type levels in hprls cells (Fig. 1E). Therefore, hprls has no effect on activation of the GAL1 promoter. This fits with the observation that induction of the endog-
Figure 1. Expression of lacZ fusion constructs placed in CEN plasmids in wild-type and hprls cells. The hpr $1 \Delta$ mutation abolished transcription through the bacterial lacZ coding region, regardless of the yeast promoter from which it was transcribed, whereas it did not affect transcription through the yeast $\mathrm{PHO} 5$ coding region. (A) The lac $Z$ coding region was fused to either the regulated GAL1 promoter or the constitutive TEF 2 and ADH 1 promoters. The PHO 5 coding region was fused to the GAL1 promoter. Numbers below each construct refer to the translation start of each DN A sequence. Expression of IacZ and PHO 5 was determined by $\beta$-galactosidase (B-D) or acid phosphatase (E) activities, respectively. For the GAL1-driven expression of either lacZ (B) or PHO 5 (C), either $2 \%$ glucose (Glu, shaded bars, $B, C, E)$ or $2 \%$ galactose (Gal, open bars, $B, C, E$ ) was added to 16-hr mid-log phase cultures in glycerol-lactate synthetic medium, and enzymatic activities were assayed $8 \mathrm{hr}$ later.

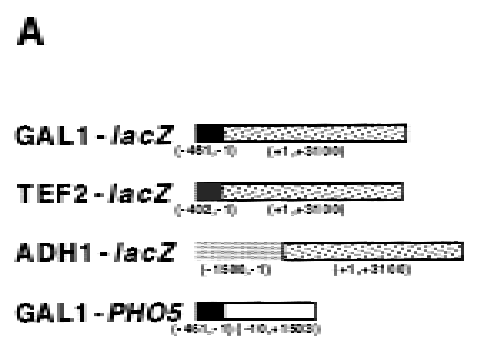

C

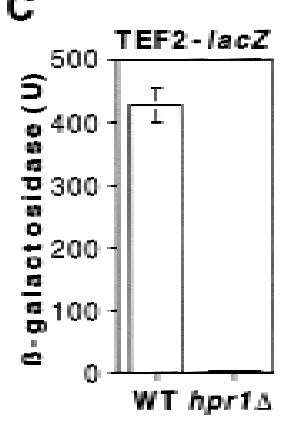

B

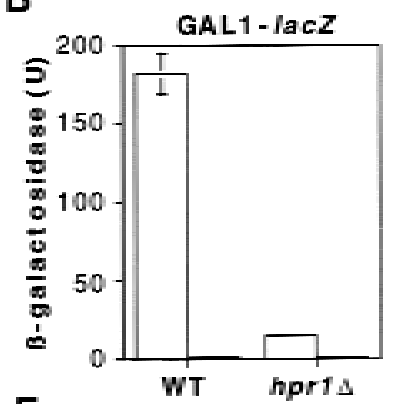

E
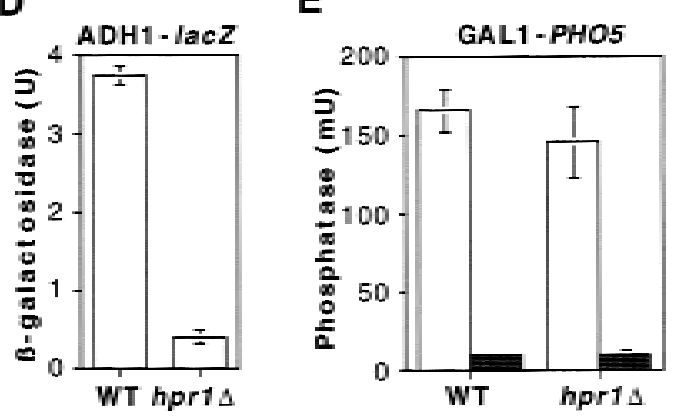
enous GAL1 gene was not affected by hprls (Fan and Klein 1994).

The previous work was performed on fusion constructs located in centromeric plasmids. Nevertheless, we have confirmed the same results in fusi on constructs located in chromosomes. Thus, Figure 2 shows that whereas acid phosphatase mainly expressed by the endogenous $\mathrm{PHO} 5$ gene reached similar level s of activation in both wild-type and hprls cells, expression of lacZ under the same PHO 5 promoter was seriously impaired in hprl $\Delta$ cells.

To confirm that the absence of $\beta$-gal actosi dase activity of hpr $1 \Delta$ cells was caused by transcriptional, rather than post-transcriptional, defects of lacZ expression, we performed N orthern analysis of IacZ under the GALI and PHO5 promoters. Figure 3 shows that lacZ mRNA driven from the GAL1 promoter was accumulated at high levels in wild type after induction, whereas it did not accumulate in hprls (Fig. 3A,B). The $\mathrm{N}$ orthern analysis of hprls cells (Fig. 3A) shows a band corresponding to the full length lacZ mRN A, which appeared with both the $5^{\prime}$ - and $3^{\prime}$-end probes of lacZ, and a smear which presumably contained incomplete $5^{\prime}$ lac $Z$ mRNAs, as it appeared with the $5^{\prime}$-end but not with the 3 '-end lacZ probe. At 30 min of induction, the total lacZ mRN A in hprl $\Delta$ (mainly incomplete 5 '-end mRNA) was produced in similar amounts as in wild-type (mainly full-length mRNA). This was consistent with the idea that the GAL1 promoter initiated transcription equally well in both wild-type and hpr $1 \Delta$, but transcription did not proceed further down from the 5 '-end region of IacZ in $h p r 1 \Delta$. The decrease of total lac Z mRNA observed after 30 min could be explained by the low stability of such incomplete transcripts (for review, see Ross 1995) and an eventual reduction in the efficiency of reinitiation of transcription from the GAL1 promoter as a consequence of a block of transcription in lacZ. Instead, PHO5 mRNA was accumulated in both wild-type and
A

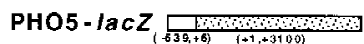

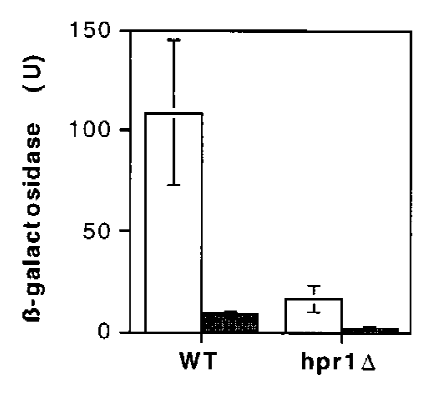

B

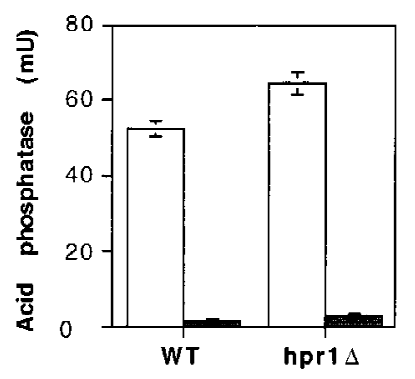

Figure 2. Expression of the chromosomally located lacZ (A) and $\mathrm{PHO} 5$ (B) coding sequences under the control of the $\mathrm{PHO} 5$ promoter in wild-type and hprls cells. For repression (+Pi, shaded bars) and induction ( $-\mathrm{Pi}$, open bars) conditions see $\mathrm{Ma}$ terial $s$ and $M$ ethods. Acid phosphatase and $\beta$-gal actosi dase were assayed in the same culture for each sample. Other details as in Fig. 1. hpr $1 \Delta$, and only full-length mRNA was observed (Fig. 3C,D).

Transcription is blocked at the lacZ $5^{\prime}$ end in hprls cells

To confirm that transcription could be paused or bl ocked at the lacZ 5'-end region we performed transcriptional run-on analysis of GAL1-lacZ in permeabilized cells (Fig. 4). RN A Pol II was paused or blocked in the first 170 bp of the lacZ 5 ' end, as deduced from the observation that under induction conditions (Gal) the amount of radiolabeled mRNA hybridizing with the first 170 bp of lacZ in hpr $1 \Delta$ was $70 \%$ of the wild-type levels (Fig. $4 \mathrm{~A}$ ), but $17 \%-39 \%$ for the next six downstream fragments. As expected, the levels of radiolabeled lacZ mRNA bound to each DNA fragment under repression conditions (Glu) was significantly lower for all DNA fragments. The only exception was the 5 '-end 170-bp fragment (Fig. 4B), which bound to similar amounts of radiolabeled mRNA under repression and induction conditions in both wild-type (101\%) and hprls cells $(74 \%)$. This implies that the polymerase is normally paused at the $5^{\prime}$ end of lac $Z$ under repression conditions as recently reported (Akhtar et al. 1996), and that the initiation of transcription is equally efficient in both wild-type and hprls cells. According to our results, Hprlp would be required to allow the RNA Pol II to travel farther down from the lac $Z$ 5'-end region under activation conditions, but not for the establishment of the RNA Pol II at the 5' end, as is also the case for Kin28p, Srb2p, or the carboxy-terminal domain (CTD) of RNA Pol Il (Akhtar et al. 1996).

$\mathrm{N}$ atural regulatory blocks of transcription described in several eukaryotic genes (for review, see Eick et al. 1994; Bentley 1995) are near their 5 ' ends and requi re transcriptional activators to be bypassed by RNA Pol II. In contrast, the lack of lacZ expression from ADH 1 and TEF2 promoters (Fig. 1) suggests that the block of transcription at lacZ in hprls cells is promoter-independent. To confirm this, we decided to place the lac $Z$ coding sequence in the UTR of the GAL1-PHO 5 construct right after the PHO 5 stop codon (see $M$ aterial s and $M$ ethods). Thus, the RNA Pol II transcription machinery has to transcribe the complete 1.4-kb PHO 5 coding sequence before entering the IacZ sequence. As can be seen in Figure 5, full PHO5-lacZ message is produced in wild-type cells but not in hpr $1 \Delta$ cells. A smear corresponding to incomplete messages was observed in hpr $1 \Delta$ cells. Such smear is al so observed in wild-type cells, as in the GAL1-IacZ construct (see Fig. 3) suggesting that, indeed, elongation through lacZ is inefficient in yeast. A new run-on analysis of this GAL1-PHO5-lacZ fusion construct showed that elongation was mostly blocked at the 5 '-end of the lacZ coding sequence in hprls cells: The RNA Pol II engaged at the $5^{\prime}$ end of lacZ was $37 \%-53 \%$ of the RN A Pol II engaged at the PHO5 coding sequence (data not shown). This result is consistent with the run-on analysis of the GAL1-lacZ construct (see Fig. 4) and confirms that the incapacity of hprls cells to make complete 
A
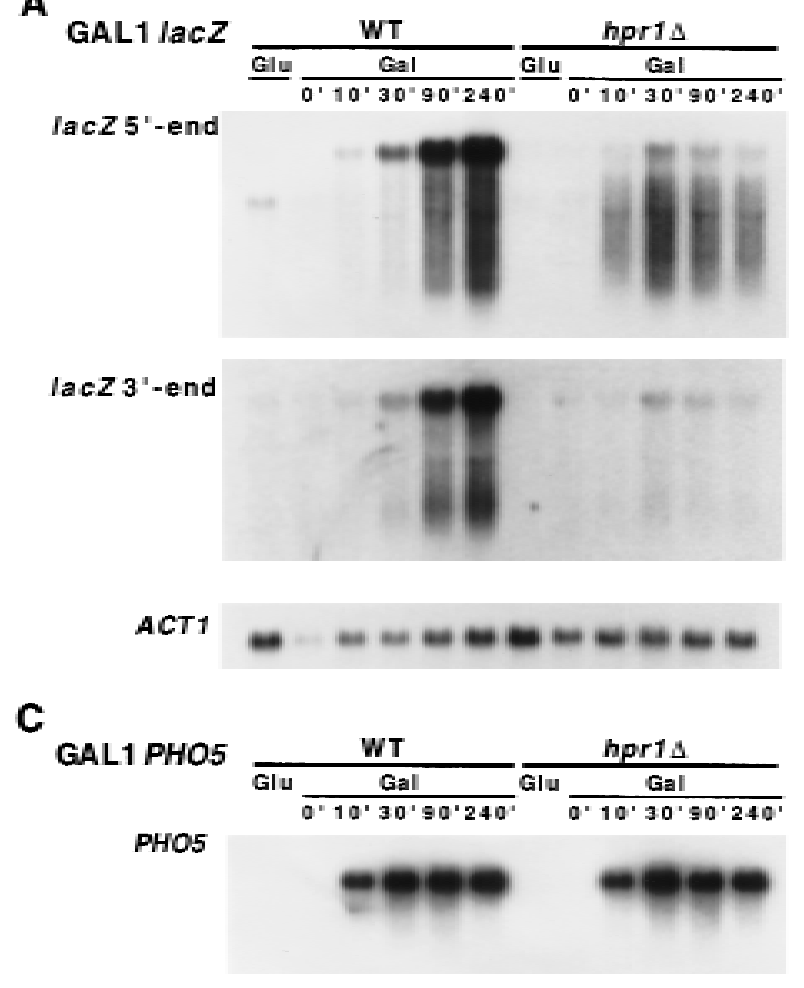

ACT1
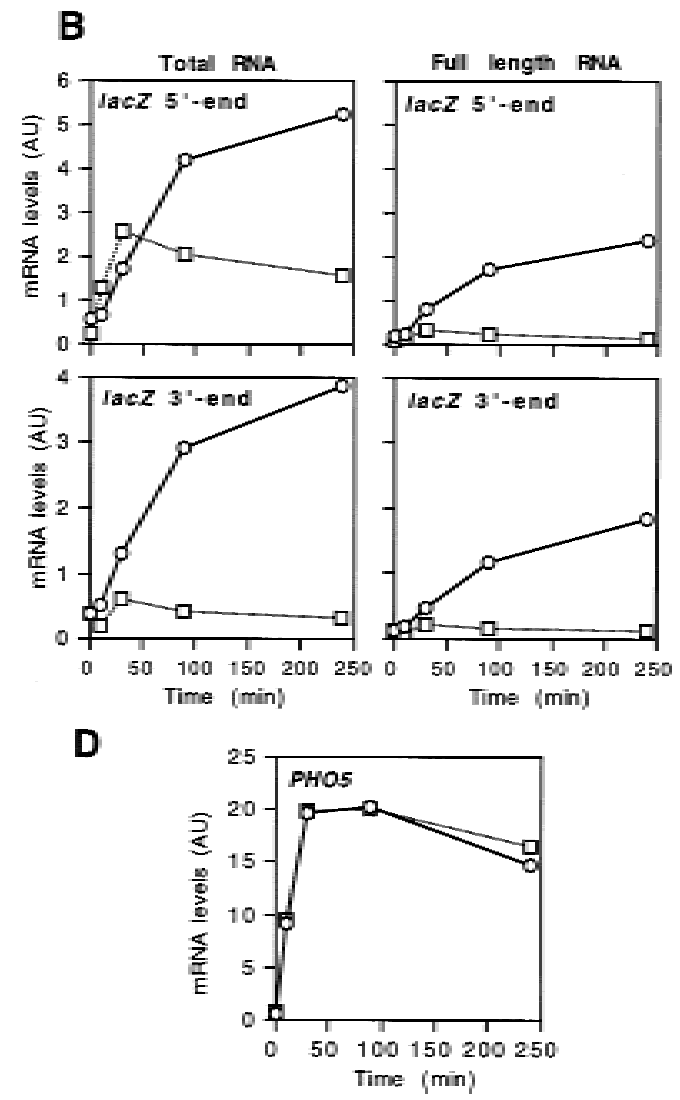

Figure 3. N orthern analysis of GAL1-lacZ and GAL1-PHO5. The Northern analysis and kinetics of induction of lacZ (A,B) and PHO5 $(C, D)$ mRN As driven from the GAL1 promoter is shown. Wild-type $(O, B, D)$ and hpr $1 \Delta(\square, B, D)$ transformants were obtained from overnight cultures in glycerol-lactate synthetic media lacking uracil and diluted in identical fresh media to an $\mathrm{OD}_{600}$ of 0.5 . Galactose (Gal) was then added and samples were taken for Northern analysis after different times, as specified. For repression conditions (Glu) total RN A was isolated from mid-log phase cultures in $2 \%$ glucose synthetic media lacking uracil. The DN A probes used were (lacZ 5' end) the 0.5-kb BamHI-H pal fragment of pLGZ containing the 5' end of lacZ; (lacZ 3' end) the 0.4-kb Pvull fragment of pLGZ containing the 5'- end of lacZ; (PHO5) the 1.5-kb EcoRI-Pstl internal PHO5 fragment of pJDB207-PHO5 (ECO); (ACT1) the 0.6-kb Clal internal ACT1 fragment of plasmid pYA301. (AU) arbitrary units.

PHO5-lacZ mRNA (Fig. 5) and lacZ mRNA (Fig. 3) is caused by the incapacity to elongate transcription through lac $Z$, regardless of its position relative to the promoter from which it is transcribed. Therefore, HPR 1 has a functional role in elongation, and not in initiation or activation of transcription.

Transcriptional elongation blocks as a cause of genome instability

To confirm that the blockage of transcription el ongation was responsible for the hyper-rec phenotype of hprl $\Delta$, we inserted the lac Z and PHO 5 coding sequences between two $0.6-\mathrm{kb}$ direct repeats, immediately downstream of a 3 '-end truncated copy of LEU 2 and immediately upstream of a 5'-truncated copy of LEU 2. In these constructs, transcription of both lacZ and $\mathrm{PHO} 5$ was initiated at the unique LEU 2 promoter, as determined by RNAse A protection (data not shown). Consequently, RNA Pol II must transcribe 760 bp of LEU 2 before en- tering either the lacZ or the PHO5 coding sequences. According to our expectations, lacZ should cause a reduction in the level of full mRN A initiated at the LEU 2 promoter and a strong hyper-recombination phenotype in hprl $\Delta$ cells, which are both consequences of blockage or stalling of transcription elongation at lacZ ( $\mathrm{L}-\mathrm{lacZ}$ constructs), but none of these phenotypes should be caused by $\mathrm{PHO} 5$ (L-PHO 5 constructs).

The results confirmed our predictions (Fig. 6). Transcription in L-lacZ constructs initiated at the LEU 2 promoter upstream of the first repeat, traversed lac $Z$ and terminated at the LEU 2 terminator downstream of the second repeat in both wild type and hprl $\Delta$. Transcript levels in hprl $\Delta$ were 12 times lower than in wild type if lacZ was transcribed in its natural direction, and 200 times if transcribed in the opposite direction, whereas recombination frequencies were increased 44- and 266fold, respectively. In the L-PHO5 constructs, both the pattern and the level of transcripts were identical in wild type and $h p r l \Delta$, and no significant difference was ob- 
A

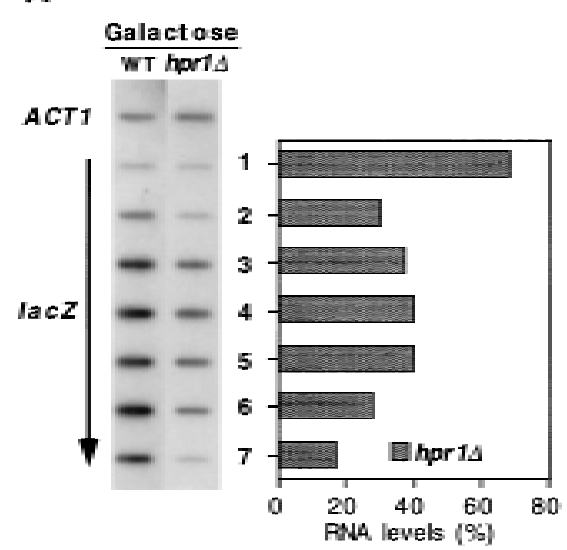

B

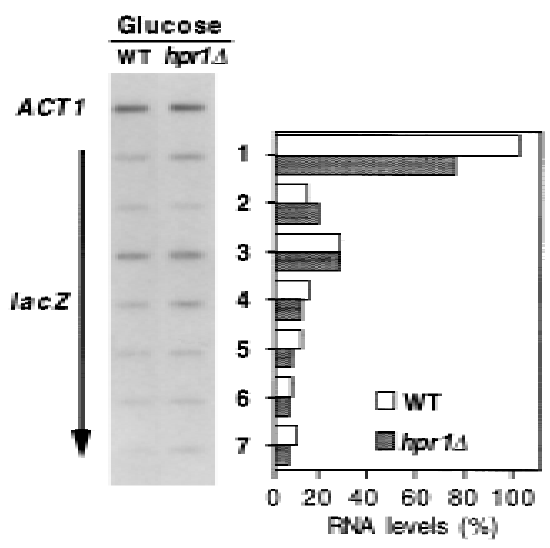

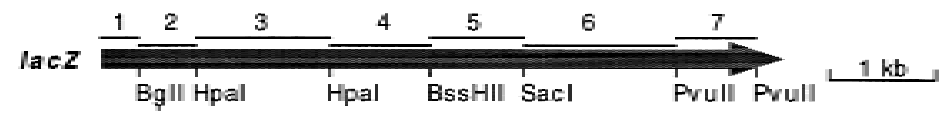

Figure 4. Transcriptional run-on analysis in wild-type and hprls cells. Total RNA was isolated from wild-type and hprl $\Delta$ cells transformed with single-copy p416GAL1lacZ plasmid under induction (A) and repression (B) conditions. Two percent-gal actose or $2 \%$ glucose was added to yeast cultures in glycerol-lactate synthetic medium at an $\mathrm{OD}_{600}$ of $0.05,5 \mathrm{hr}$ prior to the run-on analysis. The 0.6-kb internal ACT1 fragment and seven different DNA fragments (1-7) from the lacZ coding region were immobilized in hybond- $N+$ filters. The lac $Z$ region covering each of the seven DNA fragments used is shown at the bottom. In all cases, the percentage of radiolabeled mRNA bound to each lacZ fragment was normalized with respect to their corresponding levels in galactose-grown wildtype cells, taken as $100 \%$ for each. The orientation of lacZ arrows indicates the direction of transcription. As negative control, we used DNA from Salmonella typhimurium (not shown). served in recombination. In one orientation, transcription initiated at the LEU 2 promoter, traversed $\mathrm{PHO} 5$ and terminated at the $\mathrm{PHO} 5$ terminator with similar efficiency in both wild-type and hprl $\Delta$ cells (Fig. 6). A weak effect was observed on recombination (sixfold increase). In the opposite orientation, transcription terminated immediately downstream of the first LEU 2 copy once it encountered the $\mathrm{PHO} 5$ transcription terminator, with similar efficiency in both wild-type and hpr $1 \Delta$. No effect was observed on recombination.

We have also observed that the blockage of transcription at IacZ is associated with an increase in plasmid Ioss. The replicative pRS416 plasmids containing either GAL1-lacZ (p416GAL1-lacZ) or GAL1-PHO5 (pSCh202) (see Figs. 1 and 2) had similar stability in hprl $\Delta$ as in wild-type cells under repression conditions of transcription $(55 \%-62 \%$ of the cells contained the plasmids after 23-25 generations in nonsel ective gl ucose-based media). Under induction conditions, however, p416GAL1-lacZ was clearly unstable in hprl $1 \Delta$ cells. The proportion of hpr $1 \Delta$ cells that contained p416GAL1-lacZ after 23-25 generations in nonselective galactose-based media was 37 times lower than that of wild-type cells, whereas only a threefold reduction was found for pSCh202 (data not shown).

Genome instability and transcription defects of hpr $1 \Delta$ cells are observed in yeast DNA sequences in the presence of 6-azauracil

Because transcriptional el ongation block, hyper-recombi nation, and plasmid loss were only associated with the bacterial lacZ sequence in this study, it was important to investigate the role of $\mathrm{Hprlp}$ in transcription and genome instability of yeast DN A sequences. Despite HPR 1
A

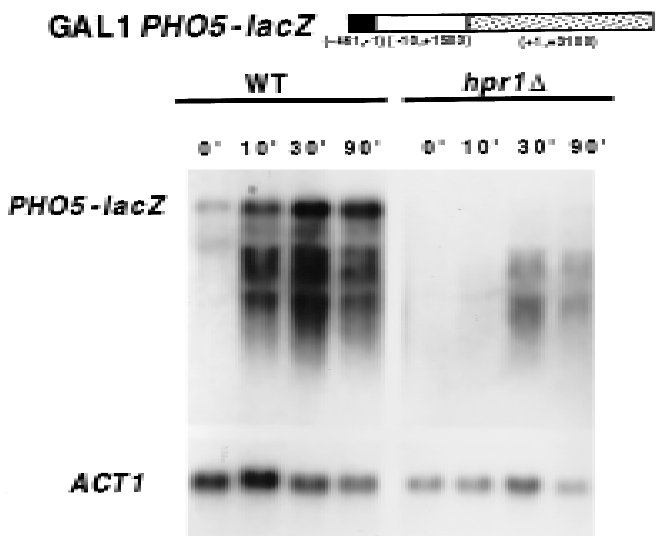

B
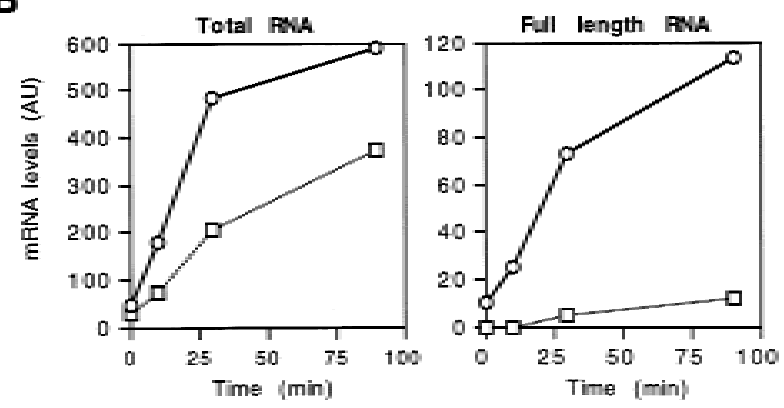

Figure 5. (A) N orthern analysis of PHO5 mRNA. The DNA probe used for $\mathrm{N}$ orthern analysis was the 1.5-kb EcoRI-Pstl internal PHO 5 fragment of pJDB207-PHO5 (Eco). Arbitrary units of mRNA were calculated according to the same standards for all experiments. (B) The mRN A values are given with respect to rRN A levels (see Materials and Methods). (O) Wild type; ( $\square$ ) hprl $1 \Delta$. Other details as in Fig. 3. 
A

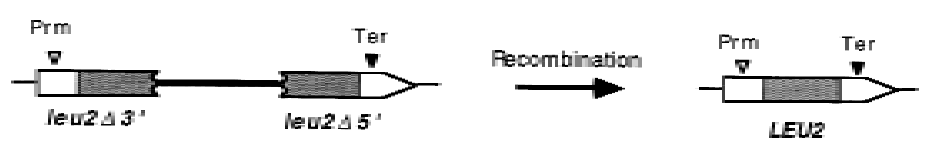

B

Figure 6. Transcription and recombination analysis of direct repeat systems carrying lacZ (3 kb) or PHO5 (1.5 kb) coding regions. A scheme of the del etion product formed by recombination between the direct repeats used is shown (A). The diagram of each direct repeat system indicates the $0.6-k b$ repeated sequences (shaded boxes), the orientation of the lacZ and PHO 5 coding regions, the LEU 2 promoter (Prm) and transcription terminators (Ter), and the transcripts driven from the LEU 2 promoter (arrow), whose 3' ends have been made to coincide with the position of the corresponding band in each gel (B). Total RNA was isolated from overnight cultures in synthetic media lacking tryptophan. The DNA probes used in the hybridization experiments were the 598bp Clal-EcoRV LEU 2 repeat, and the 581bp Clal internal ACT1 fragment. The transcript corresponding to the LEU 2 endogenous chromosomal band is indicated. No transcript initiates in the internal lac $Z$ and PHO5 internal sequences as determined with specific lacZ and PHO5 DNA probes (data not shown).

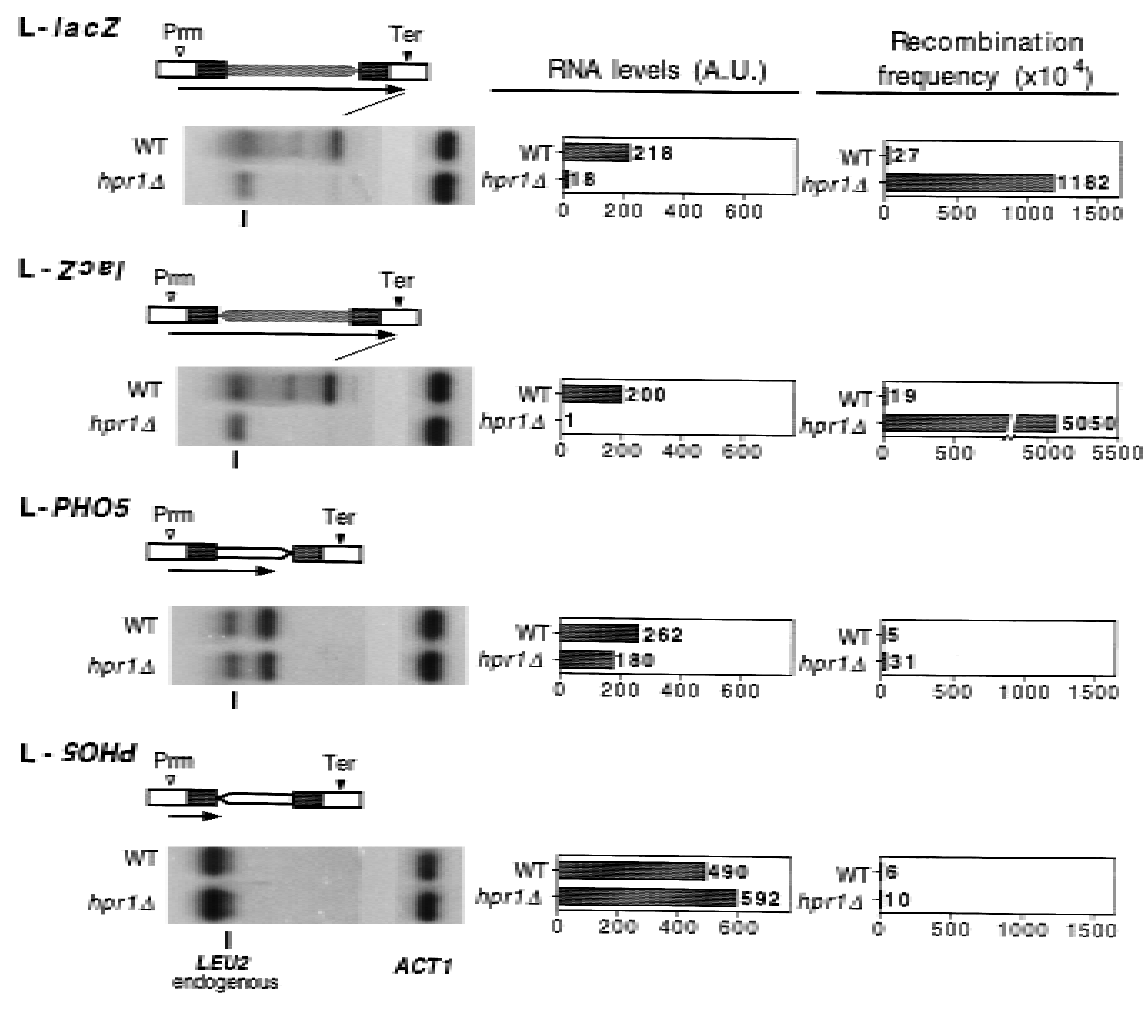

not being essential for viability, we considered the possibility that Hprlp had a general role on transcription elongation of yeast genes, as it is the case of PPR2 encoding elongation factor TFIIS (for review, see Kane 1994). Because it was shown previously that 6-azauracil (6AU) produces a depl etion of UTP and GTP responsible for a reduction of transcriptional elongation efficiency, and that the growth of mutants in PPR2 was sensitive to 6AU (Archambault et al. 1992; Exinger and Lacroute 1992), we decided to determine whether the transcription and genetic instability phenotypes conferred by hprls were also observed in yeast genes in the presence of $6 \mathrm{AU}$. We tried three different concentrations of $6 A U(100,300$, and $1000 \mu \mathrm{g} / \mathrm{ml})$. Both wild-type and $h p r 1 \Delta$ cells, in contrast to transcriptional el ongation TFIIS ${ }^{-}$mutants, were able to grow on SC media containing the three different concentrations, although hprls growth was more severely affected than wild-type growth (data not shown). When we analyzed transcription of the yeast PHO5 sequence under the GAL1 promoter, however, the kinetics of accumulation of $\mathrm{PHO} 5$ mRN A was severely affected in hprl $\Delta$ in the presence of $6 \mathrm{AU}$ (Fig. 7). Thus, the level of activation of PHO5
mRN A at 90' of induction in wild-type cells was sevenfold higher than in hprls cells. PHO 5 transcript levels increased up to sixfold at $90^{\prime}$ of induction in wild-type cells, no increase was observed in hprl $\Delta$ cells in the presence of 6AU. The ACT1 transcript levels were al so twofold lower in hprls versus wild type in the presence of $6 \mathrm{AU}$, indicating that $6 \mathrm{AU}$ specifically impairs transcription in hpr $1 \Delta$ cells (data not shown). To confirm that the observed effect of $6 \mathrm{AU}$ on transcription in hprls cells was caused by impairment of transcription elongation and not by side-effects of $6 \mathrm{AU}$, we determined whether guanine $(100 \mu \mathrm{g} / \mathrm{ml})$ could partially revert the effect of $6 \mathrm{AU}$, as shown previously for mutants of TFIIS and not for $6 \mathrm{AU}$-sensitive mutants unaffected in transcriptional elongation (Archambault et al. 1992). Figure 7 shows that accumulation of PHO 5 mRNA was reestablished by guanine in the presence of 6AU.

In addition, in the L-PHO5 construct containing the PHO5 ORF between the leu 2 repeats in the orientation that is transcribed, recombination was enhanced 14-fold over the wild-type levels in the presence of 6AU, clearly above the increase observed without 6AU (5.5-fold) (Fig. 8). In the L-PHO5 construct with $\mathrm{PHO} 5$ in the orienta- 
A

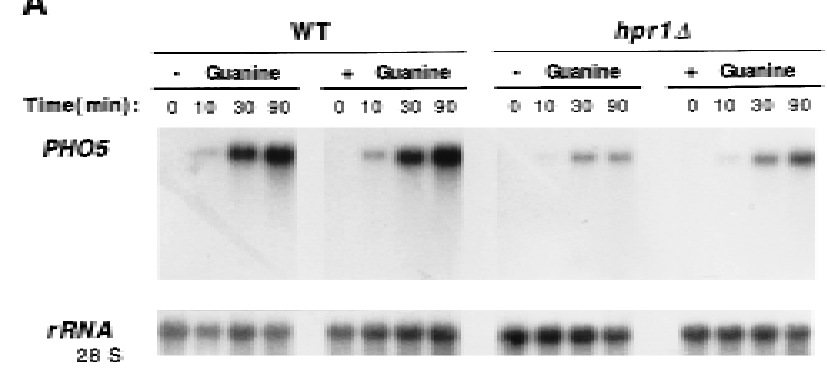

B

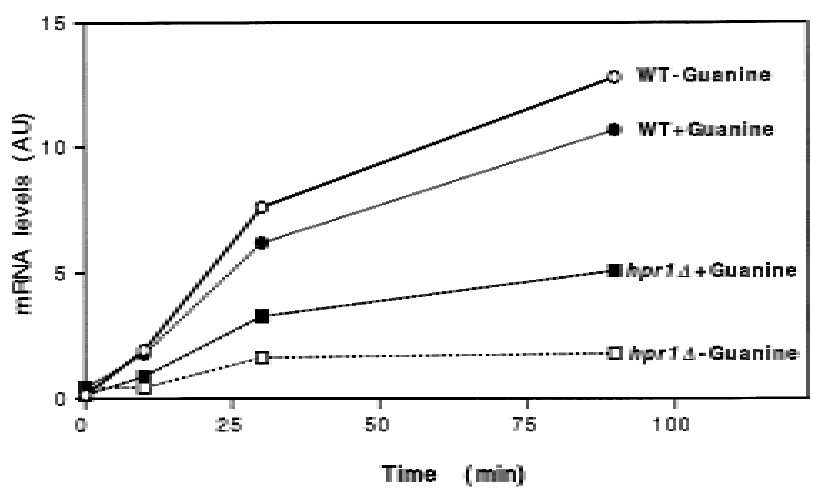

Figure 7. Transcription analysis of a yeast ORF in the presence of $6 \mathrm{AU}$. N orthern analysis (A) and kinetics of induction (B) of PHO5 mRNAs driven from the GAL1 promoter in the presence of $6 A U$ with and without guanine are shown. The $U R A 3^{+}$wildtype and hprls strains transformed with pSCh202 were obtained from overnight cultures in glycerol-lactate syntheticcomplete media lacking tryptophan and uracil, and diluted in identical fresh media to an $O D_{600}$ of 0.5 with $100 \mu \mathrm{g} / \mathrm{ml}$ of $6 \mathrm{AU}$ with and without $100 \mu \mathrm{g} / \mathrm{ml}$ of guanine. Galactose was added after $2 \mathrm{hr}$, and samples were taken for $\mathrm{N}$ orthern analysis after different times, as specified. The mRN A values are given with respect to rRNA levels (B) (see Materials and M ethods). Other details as in Fig. 3.

tion that is not transcribed, the presence of 6-AU had no effect on recombination (Fig. 8). This result clearly indicates that recombination is increased only when transcription is elongated through PHO5. Indeed, this increase in recombination correl ated with a slight decrease of transcript levels in hprl $\Delta$ cells in the presence of 6AU (data not shown). A similar effect was observed with the LA construct, containing the ADE2 gene between the leu2 repeats (data not shown), suggesting that the effect of $6 \mathrm{AU}$ on hprl $\Delta$ cells may be associated with el ongation through yeast DN A sequences. No increase of recombination in the L-lacZ construct was observed by the the addition of $6 \mathrm{AU}$ (Fig. 8), suggesting that transcriptioninduced recombination in this construct reaches its maximum levels without 6AU.

Finally, the use of centromeric plasmid pRS314-LA permitted us to determine directly by visual inspection the effect of hprl$\Delta$ on genomic instability in the presence of 6AU. Figure 9 shows that the ADE2 gene was extremely unstable in hprl $\Delta$ cells treated with $6 \mathrm{AU}$, as

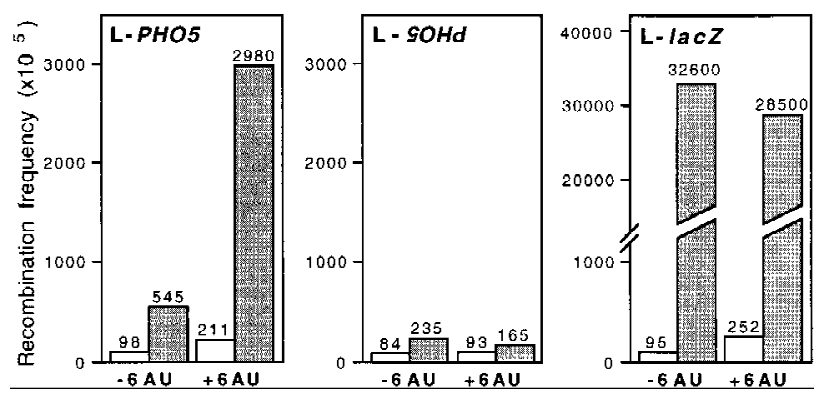

Figure 8. Recombination in the presence of $6 A \cup$. Recombination analysis of the direct repeat constructs L-lacZ and L-PHO 5 carrying the PHO 5 ORF in both possible orientations between the leu2 repeats (see Fig. 6). Recombination frequencies were determined in the $\mathrm{URA}^{+}$wild-type (open bar) and hprls (shaded bar) strains transformed with the appropriate plasmids, grown in media with or without $100 \mu \mathrm{g} / \mathrm{ml}$ of $6 \mathrm{AU}$.

shown by its red-sectoring phenotype caused by the $\mathrm{Ade}^{-}$ segregants, in contrast to untreated hprl $\Delta$ cells or wildtype cells, regardless of being treated with $6 \mathrm{AU}$. The recombination frequency leading to $\mathrm{A} \mathrm{de}^{-}$recombinants in pRS314-LA is too low $\left(<5 \times 10^{-3}\right)$ to be detected by this sectoring assay. Therefore, the observed red-sectoring phenotype is mostly caused by plasmid loss, as confirmed by genetic analysis. As expected, the phenotype of increased plasmid loss observed in hprls cells in the presence of 6AU was reverted by guanine (Fig. 9), consistent with being caused by transcription-elongation bl ockage.

These results indicate that when transcription elongation is impaired, yeast DNA sequences, and not only bacterial sequencies such as lacZ, become genetically unstable in hprls cells.

\section{Discussion}

The main conclusion of this work is that HPR1, originally identified by the hyper-recombination phenotype conferred by hprl mutations, participates in transcriptional elongation. We show that the block of transcriptional elongation produced in hprls cells is responsible
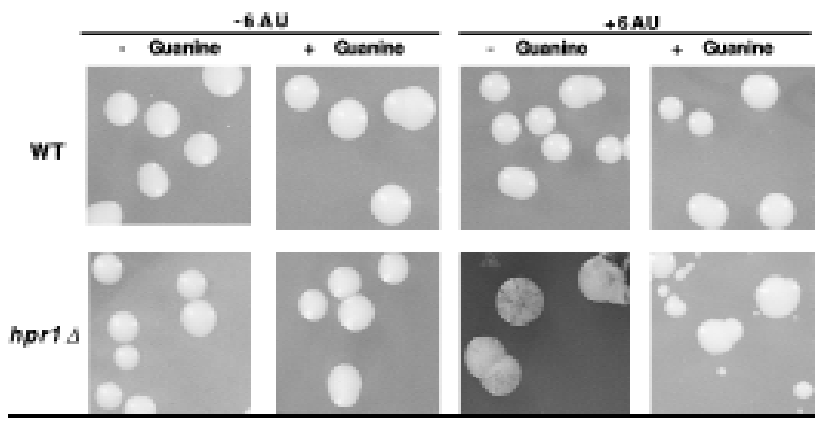

Figure 9. Plasmid instability in the presence of $6 \mathrm{AU}$. Y east colonies of $U R A 3^{+}$wild-type and hprls strains transformed with centromeric plasmid pRS314-LA growing on SC -Trp with or without $100 \mu \mathrm{g} / \mathrm{ml}$ of $6 \mathrm{AU}$ and with or without 100 $\mu \mathrm{g} / \mathrm{ml}$ of guanine. 
for the high frequency of deletions between repeats and the high frequency of plasmid-loss. Our work not only shows a role for Hprlp in transcriptional elongation but also indi cates that transcriptional el ongation blocks may be an important source of genome instability and provides a molecular mechanism to explain transcriptioninduced recombination.

\section{Hprlp functions in transcriptional el ongation}

Our experiments indicate that Hprlp stimulates transcriptional elongation through lacZ in vivo. Because previous reports suggesting that $\mathrm{Hpr} 1 \mathrm{p}$ is required for transcription activation are based on the analysis of expression of a lacZ reporter fused to different yeast regulated promoters (Fan and Klein 1994; Zhu et al. 1995), we should reinterpret those results as being caused by the incapacity of $h p r l \Delta$ cells to elongate transcription through lacZ. This is independent of whether the promoters used are constitutive or regulated (Figs. 1 and 2) and whether the lac $Z$ sequence is proximal or distal to the promoter from which it is transcribed (Figs. 3, 5, and 6). Because no effect on transcription was observed when the yeast PHO 5 ORF was used as reporter (Figs. 1 and 2), we conclude that Hprlp is not involved in transcriptional activation. Our results solve the paradox of why activation of endogenous yeast genes is not affected by hprl $\Delta$ (Fan and Klein 1994; Zhu et al . 1995). When minor effects are detected, as is the case of SU C2 (Zhu et al. 1995), they are likely to be caused by a reduced efficiency in elongation. Certainly, our study raises serious concerns about using lacZ to study transcription in yeast and invalidates previous conclusions suggesting a role for H prlp in transcriptional activation of promoters (Zhu et al. 1995).

The strong effect of hprl $\Delta$ on transcriptional elongation through lacZ is not observed in yeast genes such as $\mathrm{PHO} 5$ at $30^{\circ} \mathrm{C}$ (Fig. 3), even though a weak effect is detected at $37^{\circ} \mathrm{C}$ (S. Chávez and A. Aguilera, unpubl.). The effect of hprls on elongation of yeast genes may be masked by other redundant functions. Indeed, the observation that in the presence of the transcriptional elongation inhibitor 6-azauracil, PHO5 mRNA accumulation is strongly impaired in hpr $1 \Delta$ mutants, a phenotype partially reverted by guanine, suggests that indeed $\mathrm{H}$ prlp has a general role in transcriptional el ongation of yeast genes. Because hprl $\Delta$ are viable in 6-azauracil, the role of Hprlp in transcriptional elongation must be different from that of TFIIS, a factor required for the relief of an arrested RNA Pol II (for review, see Reines 1994). The function of Hprlp cannot be related to TFIIS, because TFIIS is inhibited by Sarkosyl (Reines 1992), used in our run-on experiments. If that were the case, no difference between wild type and hpr $1 \Delta$ should have been observed in the pattern of the pausing of RNA Pol II at lacZ (Fig. 4). Instead, H prlp might be required for preventing arrest of RNA pol II, as it has been proposed for TFIIF, elongin, or ELL (eleven-nineteen lysine-rich leukemia) (Price et al. 1989; Aso et al. 1995).

We do not know the nature of the signal on which
RNA Pol II is blocked in the absence of Hprlp. DNA bends or a particular chromatin structure of the bacterial lacZ sequence (for review, see Kane 1994; Bentley 1995) may determine the need for H prlp for its transcription, in particular at the upstream 170 nucleotides where the major hprl-dependent transcriptional block maps (Fig. 4). In this sense, it is noteworthy that $\sin 1$ (spt2) mutations, affected in a HMG1-like gene, suppress the transcriptional phenotype of hprl$\Delta$ (Zhu et al . 1995) and that SIN 1-2 and the imbal ance of histones H2A/H2B or H3/ $\mathrm{H} 4$ produced synthetic lethality in hprld (Fan and Klein 1994; Zhu et al. 1995). In addition, promoter-proximal pausing during transcriptional elongation in the human hsp70 gene depends on nucleosome templates in vitro (Brown et al . 1996). Other types of signals cannot be dismissed, however, such as those depending on RNA stems (Reeder and Hawley 1996). In any case, the transcriptional block caused by $h p r l \Delta$ at lacZ is different from RN A Pol II transcriptional pausing in other eukaryotic genes, because the latter is controlled by transactivators as an integral part of the initiation step (Yankulov et al. 1994), whereas the block at lacZ is independent of (1) its position relative to the promoter, whether proximal or distal (Figs. 5 and 6), and (2) the type of promoter to which it is fused, whether regulated or constitutive (Figs. 1 and 2). In this sense, it is particularly relevant the observation that the lac Z coding sequence abolishes production of full-length transcript when fused to the $3^{\prime}$ untranslated region ( $3^{\prime}$ UTR) of PHO5 (Fig. 5).

Finally, our results open the possibility that the synthetic lethal ity of hprl topl mutants (A guilera and Klein 1990) could be related to the role of Hprlp on transcription elongation, because topoisomerase I is also needed in RN A Pol II transcription (Schultz et al. 1992). In this sense, it is important to note that mutations in different TOP genes also confer hyper-recombination of different DN A repeats in yeast (Christman et al. 1988; Wallis et al. 1989). An in vitro-reconstituted system would be required to assess whether the transcriptional blocks caused by hprls is caused by nucleosomes, DNA sequence, or an RNA secondary structure. In any case, our results show clearly that in vivo transcriptional elongation is blocked at lacZ in a promoter-independent manner and impai red at DN A sequences such as PHO 5 in the presence of $6 \mathrm{AU}$. We find no evidence for a rol e of $\mathrm{H}$ pr $1 \mathrm{p}$ on transcription activation of promoters.

\section{Transcriptional el ongation blocks lead to genome instability}

Our work shows that hyper-recombination and plasmid instability in hpr $1 \Delta$ cells is produced in association with a transcriptional el ongation block. This explains our previous observation that hyper-recombination was dependent on transcription progression through particular DNA regions that include the bacterial tet and amp sequences (Prado et al . 1997). A strong increase in del etions between repeats and plasmid loss is observed in hprls cells only when transcription is elongated through the lacZ sequence (Fig. 6) or progresses through yeast DN A 
Transcriptional elongation and genome instability

sequences (Fig. 7) in the presence of the transcriptional elongation inhibitor 6AU. In this sense, it is particularly relevant that in the absence of $6 \mathrm{AU}$ in hprl$\Delta$ cells, a weak but significant increase in recombination was observed in the L-PHO5 construct (sixfold) when transcription elongated through PHO5, but no effect was observed when PHO5 was not transcribed. This strengthens our conclusion that Hprlp participates in transcription elongation through yeast DNA sequences. Our results provide evidence that blockage of transcription elongation leads to genomic instability of DNA repeats and offers an alternative model to explain transcription-induced recombination to those proposed previously (Blackwell et al. 1986; Voelkel-Meiman et al. 1987; Stewart and Roeder 1989; Thomas and Rothstein 1989; Nickoloff 1992). Recombination in hprls is different from previously reported cases of transcription-induced recombination, in which an increase in recombination is associated with an increase in transcript levels.

To explain how a transcriptional block can induce both a deletion between repeats and the loss of a plasmid or chromosome, we propose that a stal led transcri ptional elongation complex may induce DNA breaks or may cause an arrest of the replication fork, that would be either repaired or bypassed, respectively, by recombinational repair (see Fig. 10). Concerning the possi bility that genomic instability could arise as a consequence of the arrest of the replication fork after colliding with the blocked RN A Pol II (Fig. 10), it has been shown recently that DNA replication forks transiently arrest at highly transcribed DNA regions in yeast (Deshpande et al. 1996), and it is known that mutations in DNA Pol I and Pol III lead to an increase in chromosome loss and recombination (Hartwell and Smith 1985; Aguilera and Klein 1988). If the replication fork collided with the blocked RNA Pol II, either the 3' end of the nascent DNA could invade the other DNA-repeat region beyond the block, generating a deletion by one-ended invasion, or a cut could occur in the template leading to a doublestrand break (Fig. 10e) that would be repaired by a deletion event through either single-strand annealing (Lin et al. 1984) or one-ended invasion (Prado and Aguilera 1995). The latter possibility would fit with the recent observation that replication arrests cause double-strand breaks in Escherichia coli (Michel et al. 1997), and could explain the high frequency of recombination induced by converging replication and transcription machineries (Vilette et al. 1992). Finally, if DN A breaks induced by transcriptional blocks were not repaired, they would cause plasmid or chromosome loss (Fig. 9; Santos-Rosa and Aguilera 1994).

Although we do not have evidence that the transcription machinery itself could participate in the recruitment of recombination proteins, similar to what is believed to occur in transcription-coupled nucleoti de excision repair (for review, see Basthia et al. 1996; Hoeijmakers et al. 1996), this is a possibility that cannot be dismissed. Thus, some transcription factors present in an el ongating RNA Pol II might serve to recruit the recombination machinery that would repair the DNA

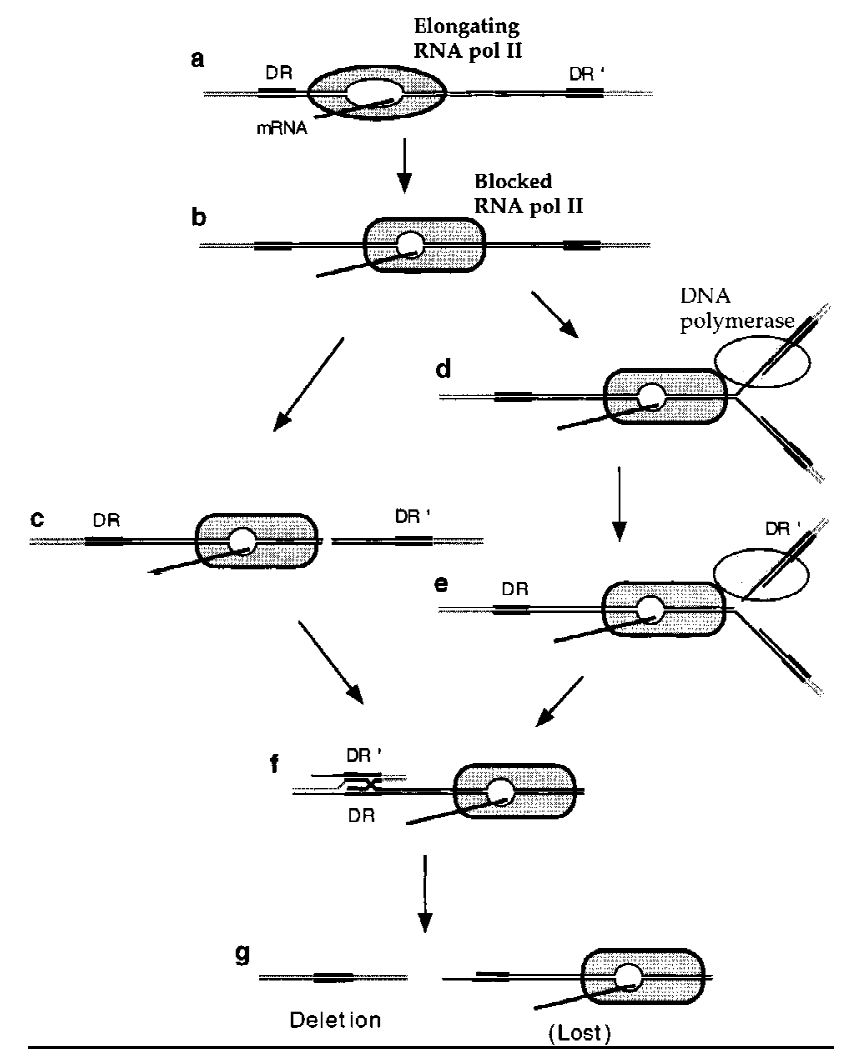

Figure 10. Alternative model s to explain induction of genomic instability by a transcriptional el ongation block. An elongating RN A Pol II (a) would be blocked at particular DN A sequences in the absence of $\mathrm{H}$ prlp in a regi on located between direct repeats DR and DR' (b). The RN A Pol II-DNA complex may facilitate DNA breaks, whether or not mediated by a nuclease (c) or may impede progression of the replication fork (d). The collapsed replication fork could eventual ly facilitate the break of the template strand leading to a double strand break (e), although this step might not be necessary. From either step (c-e), and presumably after exonuclease digestion of one DN A strand, strand pairing between $D R^{\prime}$ and $D R$ (f) facilitated by either single-strand annealing, one-ended invasion, or DN A polymerase strand slippage would cause a deletion event and the loss of the intervening region (lost) (g), explaining the hyper-recombination phenotype of $h p r 1 \Delta$. Otherwise the DN A molecule, either a plasmid or a chromosome, would be lost, explaining the high levels of chromosome and plasmid loss of hprls cells.

breaks occurring as a consequence of a transcriptional block. In this sense, it is noteworthy that the identification of Rad51p in the human RNA Pol II holoenzyme (Maldonado et al. 1996) and the finding that Srb2p and Hrslp, two RNA Pol II general transcription factors, are required for hprl $\Delta$-induced recombination (Piruat and Aguilera 1996; Piruat et al. 1997).

In summary, regardless of the mechanism leading to deletions in association to transcriptional elongation blocks, our work shows that failures in transcriptional el ongation may be an important source of genome instability, as assessed by recombination between repeats and plasmid instability. 


\section{Materials and methods}

Strains and plasmids

Strains used were the wild-type W303-1A (MATa ade2-1 can1100 his3-11,15 leu2-3,112 trp1-1 ura3-1) and its isogenic hpr1s mutant U 678-4C. Isogenic U RA $3^{+}$derivatives of W303-1A and U 678-4C were obtained by transformation with the 0.9-kb PstlSmal U RA 3 fragment. All plasmids used were based on the pRS series of single-copy autonomously replicating vectors. Plasmids p416GAL1-IacZ, p426TEF-lacZ and p416ADH-IacZ contain the lacZ coding region fused to the GAL1, the TEF2, and the ADH1 promoters, respectively (M umberg et al. 1994, 1995). Plasmid pSCh202, containing the GAL1-PHO5 fusion was constructed by cloning the 1.6-kb EcoRI-HindlII PHO5 coding region from pJDB207-PHO5 (Eco) (B. Meyhack, CIBA-GEIGY, Switzerland) immediately downstream of the GAL1 promoter in p416GAL1 (Mumberg et al. 1994). Plasmids pSCh204 and pSCh205 containing the L-lacZ constructs were made by inserting the 3-kb BamHI lacZ gene from pPZ (Straka and Hörz 1991), in both possible orientations, into the Bglll site of pRS314LB, located between the two leu2 direct repeats (Prado and Aguilera 1995). Similarly, pSCh206 and pSC207 carrying the L-PHO 5 constructs were made by inserting the 1.5-kb Pstl PHO5 gene from pSCh202, in both possible orientations, into the Pstl site of pRS314LB, also located between the two leu2 direct repeats. Plasmid p314LADE2 is pRS314LB with the ADE2 gene between the leu2 repeats (Prado and Aguilera 1997). Plasmid p306PHO5lacZ contains the lacZ gene fused to the PHO5 promoter in the integrative pRS306 vector (Piruat et al. 1997). This plasmid was integrated at the U RA 3 locus on chromosome $V$ by transforming strains W303-1A and U678-4C after linearization with Apal.

Plasmid pSCh212 contains the GAL1-PHO5-lacZ construct, which consists of the complete lacZ ORF transcriptionally fused to the $3^{\prime}$-end UTR of the PHO 5 coding sequence placed under the GAL1 promoter. Construction of this plasmid was achieved by creating a Bglll site right after the $\mathrm{PHO} 5$ stop codon by directed mutagenesis of plasmid pSCh202 with the 23-mer oligonucleotide TAGTTATACAGATCTATTGTCTC, being CTA the stop codon in the transcribed strand and $\mathbf{G}$ and $\mathbf{T}$ the 2 bases mutated from an original $A$ each to create the Bgl II site. Directed mutagenesis was performed with the Bio-Rad kit according to Bio-Rad recommendations. In the newly created BglII site, we inserted a Bglll-Nhel-N rul-Sphl synthetic polylinker and a lacZ 3.0-kb BamHI fragment in the orientation that is naturally transcribed.

\section{Enzymatic assays}

For the analysis of GAL1-driven transcription, yeast transformants with the appropriate pRS-derived plasmids were inoculated in selective synthetic medium lacking uracil with either $2 \%$ glucose or $2 \%$ galactose to an $\mathrm{OD}_{600}$ of 0.1 . After $8 \mathrm{hr}$ at $30^{\circ} \mathrm{C}$ either $\beta$-galactosidase or acid phospatase activity was assayed as described (Guarente 1983; Haguenauer-T sapis and H innen 1984) in either permeabilized cells or whole cells, respectively. For the analysis of $\mathrm{PHO} 5$-driven transcription yeast cells from an $\mathrm{SC}+2 \%$ glucose mid-log phase, cultures were resuspended in $\mathrm{SC}(-\mathrm{Pi})$ or $\mathrm{SC}$ supplemented with $7.5 \mathrm{mM} \mathrm{Na}_{2} \mathrm{PO}_{4}$ $(+\mathrm{Pi})$ as described (Piruat et al. 1997)

\section{Northern analysis}

Three micrograms of total RN A prepared from exponential cultures in the appropriate sel ective medium were subject to electrophoresis on formal dehyde-agarose gels, transferred to $\mathrm{Hy}$ -
bond-N filters, and UV crosslinked prior to hybridization at $42^{\circ} \mathrm{C}$ in $50 \%$ formamide $5 \times$ SSPE, $1 \times$ Denhardt's solution, $1 \%$ SDS with the corresponding [ $\left.{ }^{32} \mathrm{P}\right] \mathrm{dCT}$-labeled DNA probes (Prado et al. 1997). The filters were first hybridized with either the lacZ, PHO5, or LEU 2 probe, and then rehybridized with the ACT1 probe, with previous removal of the former signals. Quantification of mRNA levels was performed in a Phosphorlmager and are given in arbitrary units. All values were normalized with respect to either the amount of ACT1 mRNA or $28 \mathrm{~S}$ rRN A detected. The rRN A was detected by hybridization with a ${ }^{32}$ P-oligolabeled 589-bp 285 rRNA internal fragment obtained by PCR by use of the 19-mer oligonucleotides TTGGAGAGGGCAACTTTGG and CAGGATCGGTCGATTGTGC.

\section{Run-on analysis}

Run-on analysis was performed according to previously described protocols (Elion and Warner 1986; Osborne and Guarente 1989) with the modifications of $C$. Birse (pers. comm.). One hundred micrograms of DNA denatured with $\mathrm{NaOH}$ from each lacZ fragment were immobilized on Hybond- $\mathrm{N}+$ filters with a pR600 Sl ot Blot (Hoefer, USA). Two percent glucose or $2 \%$ gal actose were added to yeast exponential cultures in glycerol-lactate synthetic medium lacking uracil at $\mathrm{a} \mathrm{OD}_{600}$ of 0.05 . After $5 \mathrm{hr}$, cells were washed in cold TM N buffer (10 mM Tris$\mathrm{HCl}$ at $\mathrm{pH} 7.4,5 \mathrm{~mm} \mathrm{M} \mathrm{gCl}_{2}, 10 \mathrm{~mm} \mathrm{NaCl}$ ), resuspended in 0.9 $\mathrm{ml} \mathrm{H}_{2} \mathrm{O}$ and incubated for 20 min with $0.5 \% \mathrm{~N}$-lauryl-sarcosine. After centrifuging, the supernatant was carefully discarded and the run-on reaction was performed in $150 \mu \mathrm{l}$ of $20 \mathrm{~mm} \mathrm{Tris-HCl}$ at pH 7.7, $200 \mathrm{~mm} \mathrm{KCl}, 32 \mathrm{~mm} \mathrm{MgCl}_{2}, 2 \mathrm{~mm}$ DTT, $0.5 \mathrm{~mm} \mathrm{ATP,}$ CTP, GTP, and $120 \mu \mathrm{Ci}$ of [ $\left.{ }^{32} \mathrm{P}\right] \mathrm{UTP}(>3000 \mathrm{Ci} / \mathrm{mmole})$. The reaction was stopped with $1 \mathrm{ml}$ of TMN containing unlabeled UTP. After washing with iced $\mathrm{H}_{2} \mathrm{O}$, total RN A was extracted as described (Köhrer and Dombey 1991), resuspended in $40 \mu \mathrm{l}$ of $\mathrm{H}_{2} \mathrm{O}$, and frozen at $-20^{\circ} \mathrm{C}$. Before hybridization, the RN A was treated with $40 \mathrm{~mm} \mathrm{NaOH}$ in ice, and neutralized with $40 \mathrm{~mm}$ $\mathrm{HCl}$ and $100 \mathrm{~mm}$ Tris- $\mathrm{HCl}$ at $\mathrm{pH}$ 7.5. Hybridization with the previously prepared Hybond- $\mathrm{N}+$ filter containing the different lacZ DN A probes was performed as described (Prado et al. 1997) by use of E. coli tRNA at a final concentration of $100 \mu \mathrm{g} / \mathrm{ml}$. Radiolabeled mRNA bound to each DNA fragment was quantified in a Fujix $\beta$-radiation Analyzer.

\section{Frequency of recombination and plasmid stability}

The frequency of $\mathrm{Leu}^{+}$recombinants was calculated as described previously (Prado and Aguilera 1995). Plasmid stability was assayed by determining the median frequency of plasmidcontaining cells $\left(\mathrm{Ura}^{+}\right)$from six independent colonies isolated from nonselective YEP-rich medium containing either glucose or galactose. It is important to note that plasmid-instability is only observed in nonselective media, and that all other experiments (Figs. 1-4) were performed in selective media, in which the proportion of plasmid-containing cells was the same in wild-type and hprls cells (>95\%). Transcriptional elongation inhibitor 6-azauracil was used at the concentration of 100 $\mu \mathrm{g} / \mathrm{ml}$.

\section{Acknowledgments}

We thank $C$. Birse for providing the run-on protocols and rel ated technical tips, B. M eyhack and M. Funk for plasmids, J. Jordano, $M$. Beato, and F. Prado for critical reading of the manuscript, and E. Marsh and W. Reven for style correction. This work was 
supported by a grant from Direccion General de Ciencia y Tecnologica (DGICYT, Spain) to A.A. S.C. was an M. Curie postdoctoral fellow from the European Community Training and M obility of Researchers (TMR) program.

The publication costs of this article were defrayed in part by payment of page charges. This article must therefore be hereby marked "advertisement" in accordance with 18 USC section 1734 solely to indicate this fact.

\section{References}

Aguilera, A. and H.L. Klein. 1988. Genetic control of intrachromosomal recombination in Saccharomyces cerevisiae. Isolation and genetic characterization of hyper-recombination mutations. Genetics 119: 779-790.

- - . 1990. HPR1, a novel yeast gene that prevents intrachromosomal excision recombination, shows carboxy-terminal homology to the Saccharomyces cerevisiae TOP1 gene. Mol. Cell. Biol. 10: 1439-1451.

Akhtar, A., G. Faye, and D.L. Bentley. 1996. Distinct activated and non-activated RNA polymerase II complexes in yeast. EMBO J. 15: 4654-4664.

Archambault, J., F. Lacroute, A. Rue, and J.D. Friesen. 1992. Genetic interaction between transcription elongation factor TFIIS and RNA polymerase II. Mol. Cell. Biol. 12: 41424152.

Aso, T., W.S. Lane, J.W. Conaway, and R.C. Conaway. 1995. Elongin (SIII): A multisubunit regulator of elongation by RN A polymerase II. Science 269: 1439-1443.

Basthia, P.K., Z. Wang, and E.C. Friedberg. 1996. DNA repair and transcription. Curr. Opin. Genet. Dev. 6: 146-150.

Bentley, D.L. 1995. Regulation of transcriptional el ongation by RN A polymerase II. Curr. Opin. Genet. Dev. 5: 210-216.

Blackwell, T.K., M.W. Moore, G.D. Yancopoulos, H. Suh, S. Lutzker, E. Selsing, and F.W. Alt. 1986. Recombination be tween immunogl obulin variable region gene segments is enhanced by transcription. Nature 324: 585-589.

Brown, S.A., A.N . Imbalzano, and R.E. Kingston. 1996. Activator-dependent regulation of transcriptional pausing on nucleosomal templates. Genes \& Dev. 10: 1479-1490.

Christman, M.F., F.S. Dietrich, and G.R. Fink. 1988. Mitotic recombination in the rDNA of $S$. cerevisiae is suppressed by the combined action of DNA topoisomerases I and II. Cell 55: 413-425.

Deshpande, A.M . and C.S. N ewlon. 1996. DN A replication fork pause sites dependent on transcription. Science 272: 10301033.

Dröge, P. 1993. Transcription-driven site-specific DN A recombination in vitro. Proc. Natl. Acad. Sci. 90: 2759-2763.

Dul, J.L. and H. Drexler. 1988. Transcription stimulates recombination. I. Specialized transduction of Escherichia coli $\lambda$ trp phages. Virology 162: 466-470.

Eick, D., A. Wedel, and H. Heumann. 1994. From initiation to elongation: Comparison of transcription by prokaryotic and eukaryotic RN A polymerases. Trends Genet. 10: 292-296.

Elion, E.A. and J.R. Warner. 1986. An RNA polymerase I enhancer in Saccharomyces cerevisiae. Mol. Cell. Biol. 6: 2089-2097.

Exinger, F. and F. Lacroute. 1992. 6-Azauracil inhibition of GTP biosynthesis in Saccharomyces cerevisiae. Curr. Genet. 22: 9-11.

Fan, H.-Y. and H.L. Klein. 1994. Characterization of mutations that suppress the temperature-sensitive growth of the hpr $1 \Delta$ mutant of Saccharomyces cerevisiae. Genetics 137: 1-12.

Fan, H.-Y., K.K. Cheng, and H.L. Klein. 1996. Mutations in the
RNA polymerase II transcription machinery suppress the hyper-recombination mutant hpr $1 \Delta$ of Saccharomyces cerevisiae. Genetics 142: 749-759.

Grimm, C., P. Schaer, P. Munz, and J. Kohli. 1991. The strong ADH 1 promoter stimulates mitotic and meiotic recombination at the ADE6 gene of Schizosaccharomyces pombe. Mol. Cell. Biol. 11: 289-298.

Guarente, L. 1983. Yeast promoters and lacZ fusions designed to study expression of cloned genes in yeast. Methods Enzymol. 101: 181-191.

Haguenauer-Tsapis, R. and A. Hinnen. 1984. A deletion that includes the signal peptidase cleavage sites impairs processing, glycosylation and secretion of cell surface yeast acid phosphatase. Mol. Cell. Biol. 4: 2668-2675.

Hartwell, L.H. and D. Smith. 1985. Altered fidelity of mitotic chromosome transmission in cell cycle mutants of S. cerevisiae. Genetics 110: 381-395.

Hoeijmakers, J.H.J., J.-M. Egly, and W. Vermeulen. 1996. TFIIH: A key component in multiple DNA transactions. Curr. Opin. Genet. Dev. 6: 26-33.

Kane, C.M. 1994. Transcript el ongation and gene regulation in eukaryotes. In Transcription: Mechanisms and Regulation (ed. R.C. Conaway and J.W. Conaway), pp. 279-296. Raven Press, N ew York, NY.

Keil, R.L. and G.S. Roeder. 1984. cis-Acting, recombinationstimulating activity in a fragment of the ribosomal DNA of S. cerevisiae. Cell 39: 377-386.

Klar, A.J.S., J.N. Strathern, and J.B. Hicks. 1981. A positioneffect control for gene transposition: State of the expression of yeast mating-type genes affect their ability to switch. Cell 25: 517-524.

Köhrer, K. and H. Dombey. 1991. Preparation of high molecular weight RN A. Methods Enzymol. 194: 398-401.

Kotani, H. and E.B. Kmiec. 1994. Transcription activates RecApromoted homologous pairing of nucleosomal DNA. Mol. Cell. Biol. 14: 1949-1955.

Lauster, R., C.-A. Reynaud, I.-L. Martenson, A. Peter, D. Bucchini, J. Jami, and J.-C. Weill. 1993. Promoter, enhancer and silencer elements regulate rearrangement of an immugl obulin transgene. EMBO J. 12: 4615-4623.

Lin, H., K. Skerle, and N. Sternberg. 1984. Model for homologous recombination during transfer of DNA into mouse $L$ cells: Role for DNA ends in the recombination process. Mol. Cell. Biol. 4: 1020-1034.

M al donado, E., R. Shiekhattar, M. Sheldon, H. Cho, R. Drapkin, P. Rickert, E. Lees, C.W. Anderson, S. Linn, and D. Reinberg. 1996. A human RN A polymerase II complex associated with SRB and DN A-repair proteins. Nature 381: 86-89.

McCormack, W.T. and C.B. Thompson. 1990. Chicken IgL variable region gene conversions display pseudogene donor preference and $5^{\prime}$ to $3^{\prime}$ polarity. Genes \& Dev. 4: 548-558.

Michel, B., S.D. Ehrlich, and M. Uzest. 1997. DNA doublestrand breaks caused by replication arrest. EMBO J. 16: 430438.

Mumberg, D., R. Müller, and M. Funk. 1994. Regulatable promoters of Saccharomyces cerevisiae: Comparison of transcriptional activity and their use for heterologous expression. Nucleic Acids Res. 22: 5767-5768.

Mumberg, D., R. M üller, and M. Funk. 1995. Yeast vectors for the controlled expression of heterologous proteins in different genetic backgrounds. Gene 156: 119-122.

N evo-Caspi, Y. and M. Kupiec. 1994. Transcriptional induction of Ty recombination in yeast. Proc. Natl. Acad. Sci. 88: 12711-12715.

Nickol off, J.A. 1992. Transcription enhances intrachromosomal homologous recombination in mammalian cells. Mol. Cell. 
Biol. 12: 5311-5318.

Osborne, B.I. and L. Guarente. 1989. Mutational analysis of a yeast transcriptional terminator. Proc. Natl. Acad. Sci. 86: 4097-4101.

Piruat, J.I. and A. Aguilera. 1996. Mutations in the yeast SRB2 general transcription factor suppress hprl-induced recombination and show defects in DN A repair. Genetics 143: 15331542.

Piruat, J.I., S. Chávez and A. Aguilera. 1997. The yeast HRS1 gene is involved in positive and negative regulation of transcription and shows genetic characteristics similar to SIN4 and GAL11. Genetics (in press).

Prado, F. and A. Aguilera. 1995. Role of reciprocal exchange, one-ended invasion crossover and single-strand annealing on inverted and direct repeat recombination in yeast: Different requirements for the RAD1, RAD 10 and RAD 52 genes. Ge netics 139: 109-123.

Prado, F., J.I. Piruat, and A. Aguilera. 1997. Recombination between DNA repeats in yeast hprl $\Delta$ cells is linked to transcription elongation. EMBO J. 16: 2826-2835.

Price, D.H., A.E. Sluder, and A.L. Greenlaf. 1989. Dynamic interaction between a Drosophila transcription factor and RN A polymerase II. Mol. Cell. Biol. 9: 1465-1475.

Reeder, T.C. and D.K. Hawley. 1996. Promoter proximal se quences modulate RN A polymerase II elongation by a novel mechanism. Cell 87: 767-777.

Reines, D. 1992. Elongation factor-dependent transcript shortening by template-engaged RNA polymerase II. J. Biol. Chem. 267: 3795-3800.

- - - 1994. Nascent RN A cleavage by transcription elongation complexes. In Transcription: Mechanisms and regulation (ed. R.C. Conaway and J.W. Conaway), pp. 263-278. Raven Press, N ew York, NY.

Ross, J. 1995. Control of messenger RNA stability in higher eukaryotes. Trends Genet. 12: 171-175.

Santos-Rosa, H. and A. A guilera. 1994. Increase in incidence of chromosome instability and non-conservative recombination between repeats in Saccharomyces cerevisiae hprls strains. Mol. \& Gen. Genet. 245: 224-236.

Santos-Rosa, H., B. Clever, W.-D. Heyer, and A. Aguilera. 1996. The yeast HRS1 gene encodes a polygl utamine-rich nuclear protein required for spontaneous and hprl-induced del etions between direct repeats. Genetics 142: 705-716.

Schultz, M.C., S.J. Brill, Q.D. Ju, R. Sternglanz, and R.H. Reeder. 1992. Topoisomerases and yeast rRN A transcription: N egative supercoiling stimulates initiation and topoisomerase activity is required for el ongation. Genes \& Dev. 6: 1332-1341.

Stewart, S.E. and G.S. Roeder. 1989. Transcription by RNA polymerase I stimulates mitotic recombination in Saccharomyces cerevisiae. Mol. Cell. Biol. 9: 3464-3472.

Straka, A. and W. Hörz. 1991. A functional role for nucleosomes in the repression of a yeast promoter. EMBO J. 10: 361-368.

Thomas, B.J. and R. Rothstein. 1989. Elevated recombination rates in transcriptionally active DNA. Cell 56: 619-630.

Thyagarajan, B., B.L. Johnson, and C. Campbel. 1995. The effect of target site transcription on gene targeting in human cells in vitro. Nucleic Acids Res. 23: 2784-2790.

U emura, H., S. Pandit, Y. Jigami, and R. Sternglanz. 1996. Mutations in GCR3, a gene involved in the expression of glycolytic genes in Saccharomyces, suppress the temperaturesensitive growth of hprl mutants. Genetics 142: 1095-1103.

Vilette, D., M. Uzest, S.D. Ehrlich, and B. Michel. 1992. DNA transcription and repressor binding affect del etion formation in Escherichia coli plasmids. EMBO J. 11: 3629-3634.

Voelkel-M eiman, K., R.L. Keil, and G.S. Roeder. 1987. Recombination-stimulating sequences in yeast ribosomal DNA correspond to sequences regulating transcription by RNA polymerase I. Cell 48: 1071-1079.

Wallis, J.W., G. Chrebet, G. Brodsky, M. Rolfe, and R. Rothstein. 1989. A hyper-recombination mutation in S. cerevisiae identifies a novel eukaryotic topoisomerase. Cell 58: 409-419.

Yankulov, K., J. Blau, T. Purton, S. Roberts, and D.L. Bentley. 1994. Transcriptional elongation by RNA polymerase II is stimulated by transactivators. Cell 77: 749-759.

Zhu, Y., C.L. Peterson, and M.F. Christman. 1995. HPR1 encodes a global positive regulator of transcription in Saccharomyces cerevisiae. Mol. Cell. Biol. 15: 1698-1708. 




\section{The yeast HPR1 gene has a functional role in transcriptional elongation that uncovers a novel source of genome instability}

Sebastián Chávez and Andrés Aguilera

Genes Dev. 1997, 11:

Access the most recent version at doi:10.1101/gad.11.24.3459

References This article cites 55 articles, 29 of which can be accessed free at:

http://genesdev.cshlp.org/content/11/24/3459.full.html\#ref-list-1

License

Email Alerting

Receive free email alerts when new articles cite this article - sign up in the box at the top

Service right corner of the article or click here.

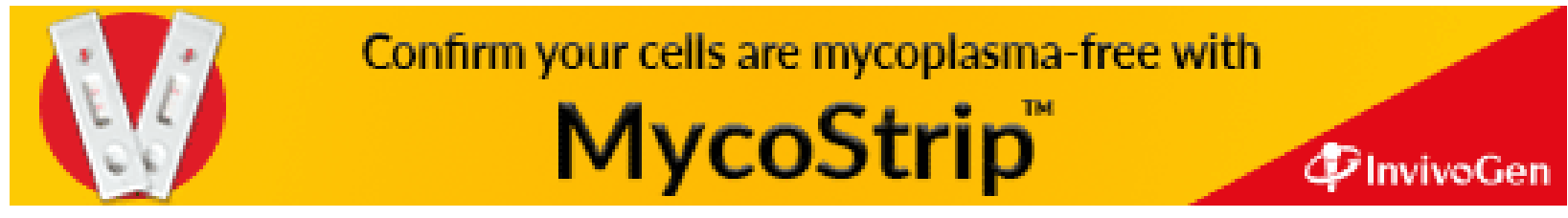

